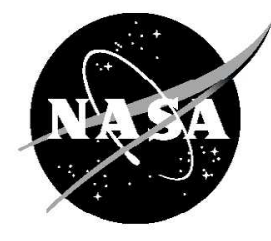

\title{
Development of a Reactor for the Extraction of Oxygen and Volatiles From Lunar Regolith
}

Julie Kleinhenz and Zengguang Yuan

National Center for Space Exploration Research, Cleveland, Ohio

Kurt Sacksteder and John Caruso

Glenn Research Center, Cleveland, Ohio 


\section{NASA STI Program . . . in Profile}

Since its founding, NASA has been dedicated to the advancement of aeronautics and space science. The NASA Scientific and Technical Information (STI) program plays a key part in helping NASA maintain this important role.

The NASA STI Program operates under the auspices of the Agency Chief Information Officer. It collects, organizes, provides for archiving, and disseminates NASA's STI. The NASA STI program provides access to the NASA Aeronautics and Space Database and its public interface, the NASA Technical Reports Server, thus providing one of the largest collections of aeronautical and space science STI in the world. Results are published in both non-NASA channels and by NASA in the NASA STI Report Series, which includes the following report types:

- TECHNICAL PUBLICATION. Reports of completed research or a major significant phase of research that present the results of NASA programs and include extensive data or theoretical analysis. Includes compilations of significant scientific and technical data and information deemed to be of continuing reference value. NASA counterpart of peer-reviewed formal professional papers but has less stringent limitations on manuscript length and extent of graphic presentations.

- TECHNICAL MEMORANDUM. Scientific and technical findings that are preliminary or of specialized interest, e.g., quick release reports, working papers, and bibliographies that contain minimal annotation. Does not contain extensive analysis.

- CONTRACTOR REPORT. Scientific and technical findings by NASA-sponsored contractors and grantees.
- CONFERENCE PUBLICATION. Collected papers from scientific and technical conferences, symposia, seminars, or other meetings sponsored or cosponsored by NASA.

- SPECIAL PUBLICATION. Scientific, technical, or historical information from NASA programs, projects, and missions, often concerned with subjects having substantial public interest.

- TECHNICAL TRANSLATION. Englishlanguage translations of foreign scientific and technical material pertinent to NASA's mission.

Specialized services also include creating custom thesauri, building customized databases, organizing and publishing research results.

For more information about the NASA STI program, see the following:

- Access the NASA STI program home page at http://www.sti.nasa.gov

- E-mail your question via the Internet to help@ sti.nasa.gov

- Fax your question to the NASA STI Help Desk at $443-757-5803$

- Telephone the NASA STI Help Desk at 443-757-5802

- Write to: NASA Center for AeroSpace Information (CASI) 7115 Standard Drive Hanover, MD 21076-1320 
NASA/TM-2009-215621

AIAA-2009-1203

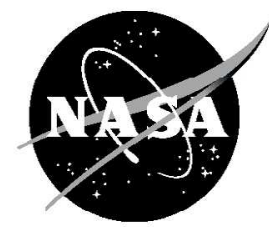

\section{Development of a Reactor for the Extraction of Oxygen and Volatiles From Lunar Regolith}

Julie Kleinhenz and Zengguang Yuan

National Center for Space Exploration Research, Cleveland, Ohio

Kurt Sacksteder and John Caruso

Glenn Research Center, Cleveland, Ohio

Prepared for the

47th Aerospace Sciences Meeting

sponsored by the American Institute of Aeronautics and Astronautics

Orlando, Florida, January 5-8, 2009

National Aeronautics and

Space Administration

Glenn Research Center

Cleveland, Ohio 44135 


\section{Acknowledgments}

Seal selection and testing early in the reactor development were performed by Margaret Proctor and Irebert Delgado. The reactor was designed by Dan Gotti, the auger and its drive assembly was designed by Dan Breen, and the electrical systems designed by William Yanis. Tommy On assisted in both experimental and modeling efforts. The authors are very grateful for their energetic contributions. Additionally, the authors gratefully acknowledge the support of this work by the

In-Situ Resource Utilization Project and the Advanced Thermal Control Project, which are part of the NASA Exploration Technology Development Program.

Trade names and trademarks are used in this report for identification only. Their usage does not constitute an official endorsement, either expressed or implied, by the National Aeronautics and Space Administration.

Level of Review: This material has been technically reviewed by technical management.

Available from

NASA Center for Aerospace Information 7115 Standard Drive Hanover, MD 21076-1320
National Technical Information Service 5285 Port Royal Road Springfield, VA 22161

Available electronically at http://gltrs.grc.nasa.gov 


\title{
Development of a Reactor for the Extraction of Oxygen and Volatiles From Lunar Regolith
}

\author{
Julie Kleinhenz and Zengguang Yuan \\ National Center for Space Exploration Research \\ Cleveland, Ohio 44135 \\ Kurt Sacksteder and John Caruso \\ National Aeronautics and Space Administration \\ Glenn Research Center \\ Cleveland, Ohio 44135
}

\begin{abstract} along with the analog site tests, will be used to evolve and optimize future reactor designs.

\section{Nomenclature}

$c \quad$ apparent specific heat of stimulant JSC-1a in air, $\mathrm{J} / \mathrm{kg}^{\circ} \mathrm{C}$

$k \quad$ apparent thermal conductivity of the stimulant JSC- $1 \mathrm{a}, \mathrm{W} / \mathrm{m}^{\circ} \mathrm{C}$

$P \quad$ pressure at given time increment, psi

$P_{0} \quad$ initial pressure of the system, psi

$R_{\text {water }} \quad$ gas constant for water

$t \quad$ time, $\mathrm{s}$

$T \quad$ temperature, ${ }^{\circ} \mathrm{C}$

$T_{\text {avg }} \quad$ average temperature of the system during the test, ${ }^{\circ} \mathrm{C}$

$V \quad$ internal volume of the reactor, $\mathrm{m}^{3}$
\end{abstract}

The RESOLVE (Regolith and Environment Science, Oxygen and Lunar Volatiles Extraction) Project, aims to extract and quantify useful resources from lunar soil. The reactor developed for RESOLVE is a dual purpose system, designed to evolve both water, at $150{ }^{\circ} \mathrm{C}$ and up to $80 \mathrm{psig}$, and oxygen, using hydrogen reduction at $\sim 900^{\circ} \mathrm{C}$. A variety of laboratory tests were performed to verify its operation and to explore the properties of the analog site soil. The results were also applied to modeling efforts which are being used to estimate the apparent thermal properties of the soil. The experimental and numerical results,

\section{Introduction}

The In-Situ Resource Utilization (ISRU) program aims to develop technologies that will be critical to future exploration missions to the Moon and Mars. One such technology is the extraction and capture of mission consumables, i.e., water and oxygen, from the lunar regolith. The goal of the RESOLVE (Regolith and Environment Science, Oxygen and Lunar Volatiles Extraction) project is to prospect for and quantify these resources and demonstrate how to extract them.

Intended as a package concept for a mobile lunar robotic mission, the RESOLVE project encompasses the collection and processing of $\sim 100 \mathrm{~g}$ batches of regolith. The system includes; extraction of regolith samples using a coring drill, crushing of the sample to an acceptable size distribution, 
characterization of bulk regolith properties and mineralogical content, evolution of volatiles in a reactor, detection of evolved gases using a gas chromatograph, and capture and rerelease of the volatiles using absorbent beds. The objective of the package is to demonstrate the feasibility of ISRU related tasks, especially volatile and oxygen extraction processes. The results of this work will be used in the design of larger-scale processing plants to be implemented as part of a lunar outpost.

An earlier laboratory-based system was a first attempt to integrate a core sampling drill, separate reactors for volatile extraction and oxygen production and evolved gas collection and analysis instrumentation. This EBU1 (Engineering Breadboard Unit) payload provided indications of the necessary system power requirements, operating conditions, and timelines (ref. 1). During the past year a second integrated package, called EBU2, was developed in which the two reactor systems were combined into a single multipurpose reactor, and the entire payload shrunk and packaged to fit into a modest size rover (ref. 2) in preparation for field trials.

This report describes the reactor subsystem of the RESOLVE project EBU2 payload, and laboratory testing conducted to assess its performance. The combined reactor performs two functions; thermal extraction of loosely bound water, including operations up to $150{ }^{\circ} \mathrm{C}$ and $80 \mathrm{psi}$, and the chemical extraction of oxygen from iron oxides using hydrogen reduction, including operations up to $900{ }^{\circ} \mathrm{C}$ at near-ambient pressures.

\section{Hardware}

The reactor developed for the RESOLVE field demonstration is a dual purpose system, designed to accommodate the high temperatures of the oxygen extraction process, while still capable of sealing to elevated pressures during volatiles extraction. Figure 1 shows images of the hardware with the corresponding line drawings. The main section of the reactor consists of a 1.38 in. ID Inconel tube. A second, welded tube section accommodates soil loading. The total internal volume of the reactor is $\sim 194 \mathrm{~cm}^{3}$.

There are four ports on the reactor to accommodate gas flow. During the oxygen extraction operation, gas flow enters at the bottom of the reactor, and exits at the top. A second port at the top accommodates gases from the volatiles extraction process. An annular sintered metal filter minimizes dust loss through these ports. A port in the entrance chute supports a pressure transducer, a 105 psi pressure burst disc, and a vent line.

Soil enters the reactor through the upper set of two ball valves by means of a funnel and flows down the chute into the main reactor body. There two more ball valves at the bottom of the reactor, one of which acts as the 'floor' of the reactor. The innermost ball valves contain regolith while the outer valves maintain a pressure seal. Vibration devices (linear solenoids) mounted to the valve casing assist soil movement by dislodging gathered dust and preventing soil bridging. Two motors are used to actuate the ball valves; one for the top two valves, and another for the bottom two.

An auger in the center of the reactor body is used to heat and mix the soil. This core heater/auger assembly enters through a slip ring at the top of the reactor where it is driven at $14 \mathrm{rpm}$. During the volatiles extraction operation an additional heater on the outer wall is used to maintain an elevated wall temperature, preventing condensation of the released water vapor. The reactor body is insulated and instrumented with thermocouples, which facilitate heater control and data feedback. Figure 2 shows the positions of these thermocouples and the labels that will be referred to in the subsequent text. 


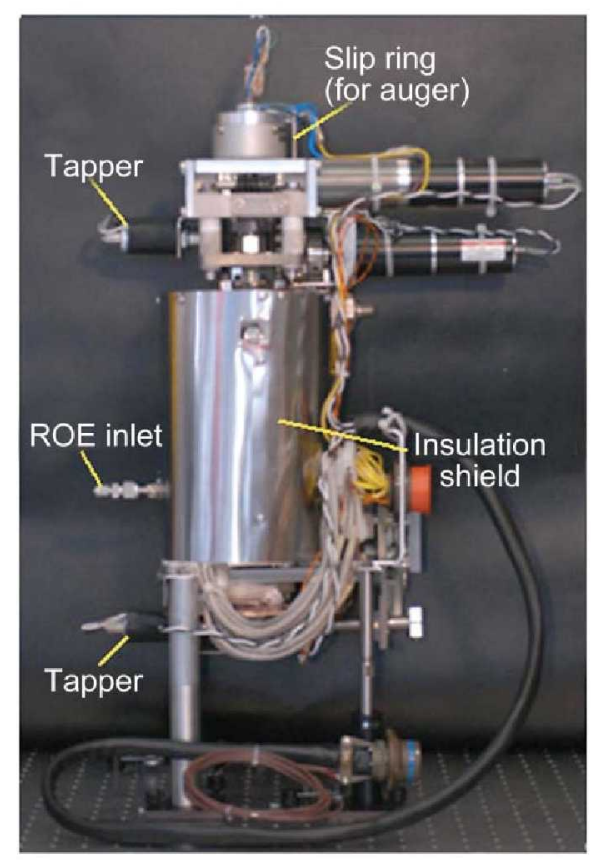

Reactor with insulation

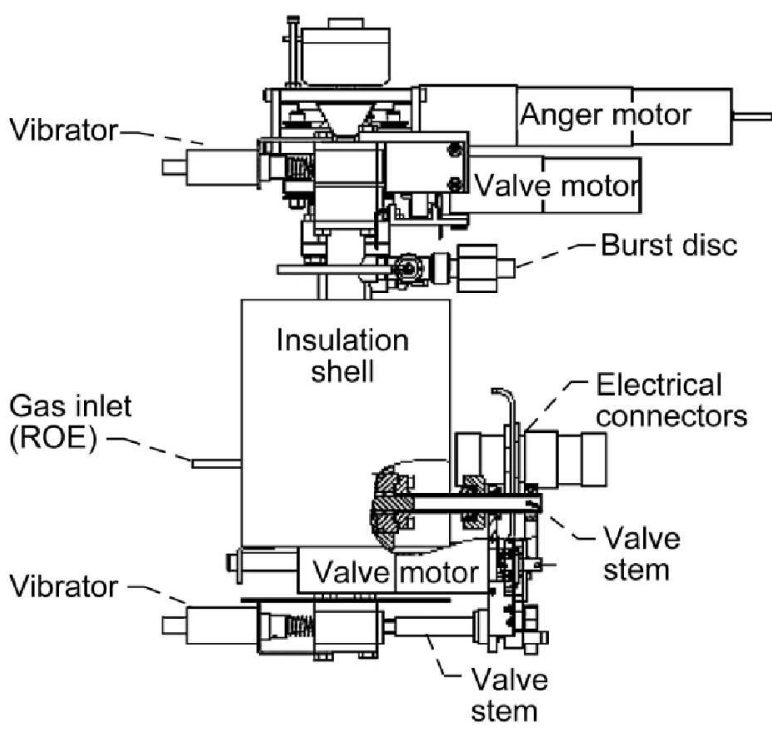

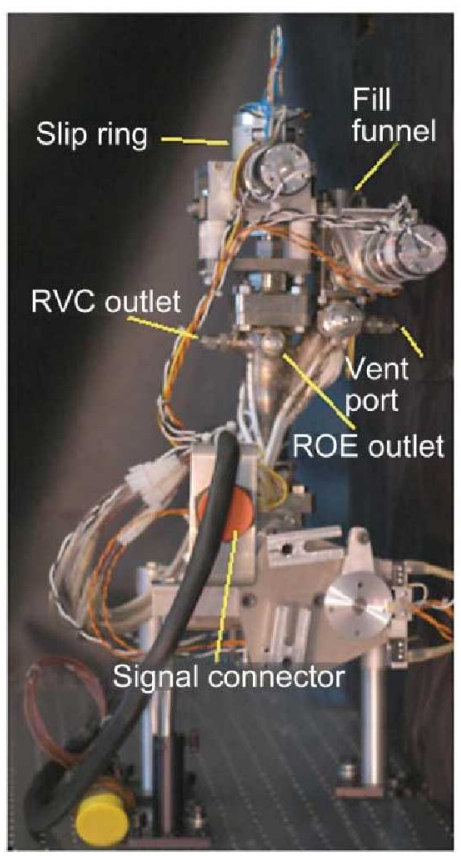

Reactor without insulation, rotation $90^{\circ}$

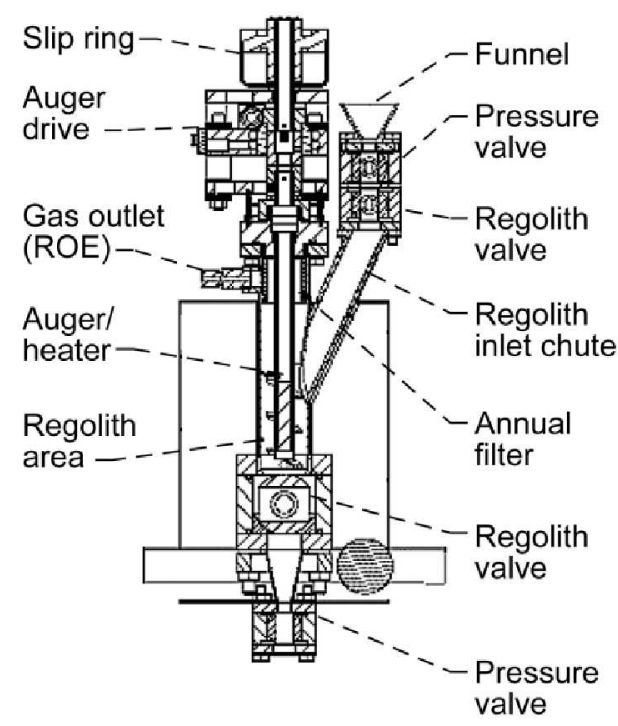

Figure 1.- Images and line drawings of the RESOLVE reactor with and without the insulation. 


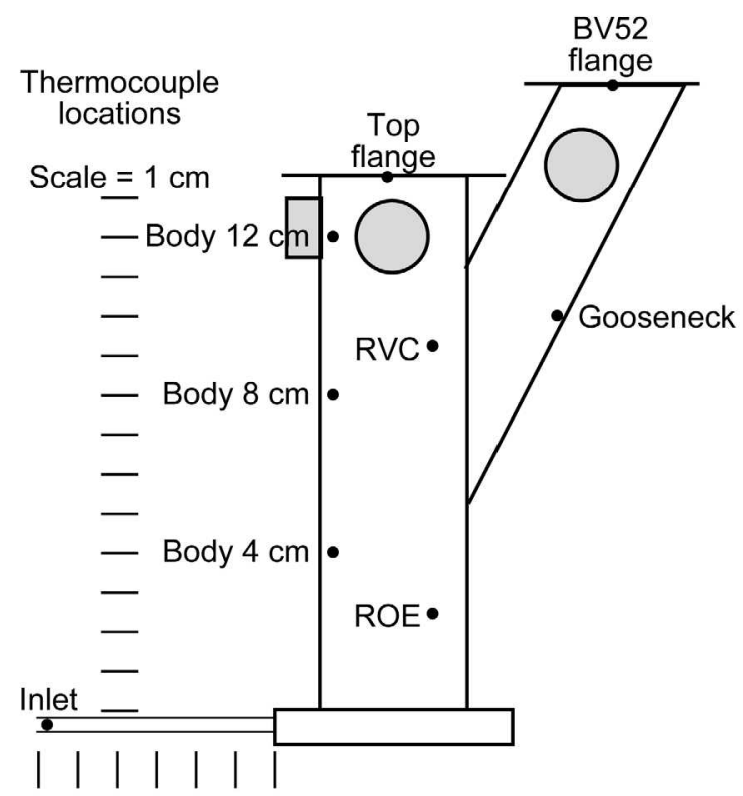

Figure 2.-Thermocouple positions on the reactor walls, and their corresponding labels.

\section{Experimental Results}

The following experimental results were gathered during bench top testing of the reactor prior to integration with the rest of the RESOLVE package. These results were used to characterize the reactor, the soil, and determine operating procedures for the integrated package. For these initial tests, a flow of air was used to study the flow effects in lieu of hydrogen.

\section{A. Seal Tests}

Lunar regolith is a particularly intrusive and abrasive material, and as such can be damaging to sealing surfaces. This combined with the high temperature and elevated pressure conditions of the reactor, made seals selection a critical design issue.

Ball valves were selected due to their low profile and resistance to wear. Double valves were used to improve their functionality. The inner ball valves use a ceramic felt seat in order to contain dust. These served to protect the outermost ball valves, which utilize PEEK (PolyEtherEtherKetone) material to maintain pressure.

The valves were evaluated experimentally by measuring pressure leak rate after successive valve cycles. One valve 'cycle' consists of opening the valve, pouring regolith simulant through, and closing the valve. The reactor vessel was pneumatically pressurized, and pressure was monitored over time to determine leak rates.

The valves were tested prior to reactor fabrication using a simplified reactor mockup apparatus with accommodated a single ball valve. Testing involved 40 consecutive valve cycles, which was the estimated life time of the seals. While not without issue, the valves showed promise and thus were incorporated into the final design. Torque values, measured during these tests, were also used in the design of the valve actuators. Both leak rate and torque increased after the first cycles, but remained consistent thereafter. While these tests demonstrated the qualitative performance of the valves, the leak rate quantities were highly conservative. This was due to the disparities between the test apparatus and the actual reactor. The tests also stressed the need for vibration devices to assist soil movement through the valves. 
Tests were performed in the assembled reactor over 5 cycles, representing the processing of one full core drill sample (there are 4 batches of soil for every core sample). These tests were done as verification of the earlier single valve tests, so an additional 40 cycles were not deemed necessary. The reactor was not heated during these tests. Since the working fluid was air, the ideal gas law was used to estimate the leak rates of water vapor. The equation used for this conversion was:

$$
\dot{m}=\frac{P_{t}-P_{0}}{t} \frac{V}{R_{\text {water }} T_{\text {avg }}}
$$

where $t$ is the time, $P_{t}$ is pressure at the given time increment, $P_{0}$ is the initial pressure, $V$ is volume of the reactor, $R_{\text {water }}$ is the gas constant of water vapor, and $T_{\text {avg }}$ is the average temperature of the reactor over the course of the test.

Figure 3 shows the results of these tests. The upper set of curves show the pressure decay over time, and corresponds to the left ordinate. The lower set of curves, corresponding to the right ordinate, shows the leak rate as it compounds over time. Each of these leak rates reference the pressure at time zero. The maximum unit of the scale is $0.05 \mathrm{~g} / \mathrm{hr}$, which is the maximum acceptable loss of water vapor (10 percent of the saturation vapor pressure at $150^{\circ} \mathrm{C}$ ) over a $1 \mathrm{hr}$ operation. These data are summarized in figure 4 , where the leak rates are plotted for each cycle at several different time steps. The leak rate is not consistent over time, but varies depending on the time increment chosen. This may have been at least partly due to the manner in which the data was taken (manually recorded at imprecise time intervals). Looking at the leak rate over the full test times of the cycles (stated numerically at the bottom of the figure) the leak rate apparently stabilizes in cycles 3 to 5 . It is important to note that this is also true using a $45 \mathrm{~min}$ time interval, which is approximately the span of a volatiles release operation. Regardless of the time increment, the leak rate never exceeded the maximum allowable limit of $0.05 \mathrm{~g} / \mathrm{hr}$. Thus the seals for the reactor have proven themselves successful for this application.

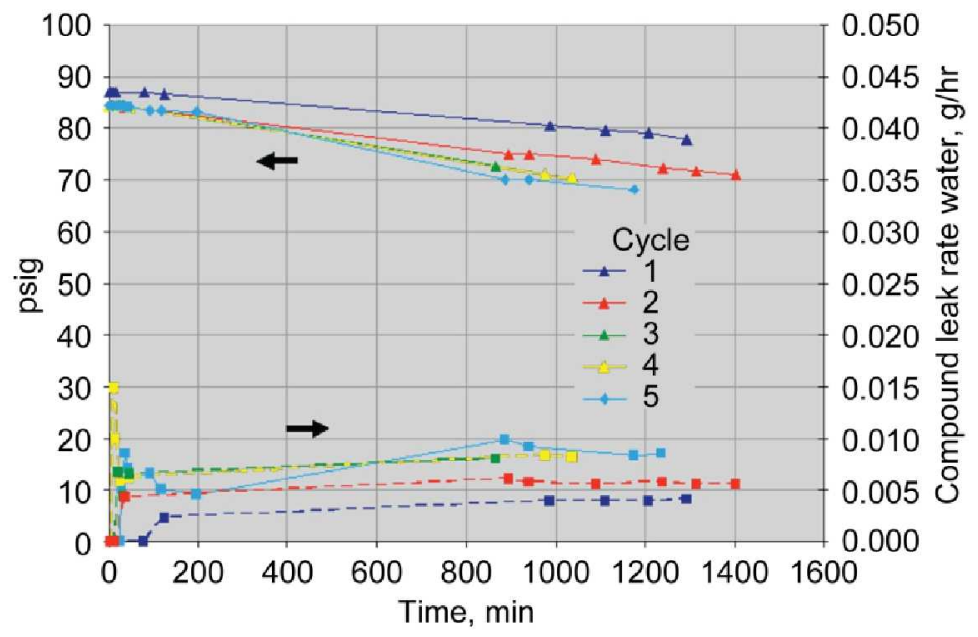

Figure 3.-Results from the seal tests on the reactor over 5 cycles. Pressure decay is plotted on the left ordinate. The leak rate of water vapor on the right ordinate, where the scale maximum corresponds to the maximum allowable leak rate for an hour's test: $0.05 \mathrm{~g} / \mathrm{hr}$. 


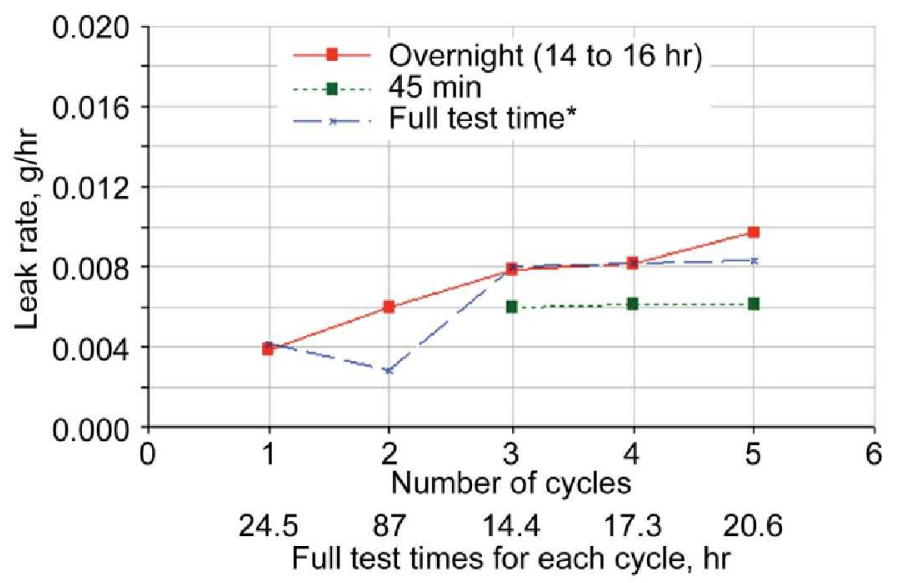

Figure 4.-The leak rates are not constant over time. There is some variation depending on the time increment chosen.

\section{B. Thermal Design}

At the high temperatures of the oxygen extraction process, conduction through the reactor body can be expected to cause many reactor components to be at elevated temperatures. Prior to fabrication, a steady state thermal model was used to estimate these temperatures. Figure 5 shows the calculated temperature distribution over the metal body of the reactor, assuming the soil region is insulated and the rest is exposed to convective cooling. The soil region is at the maximum possible temperature of $1000{ }^{\circ} \mathrm{C}$. This model was intended as a conservative estimate of the temperatures to ensure a factor of safety in the design. Reactor materials were chosen accordingly.

Once fabrication was complete, a test was conducted to monitor temperatures at some critical locations to verify that they were within these design limits. Figure 5 shows the locations of most of the thermocouples, while figure 6 shows their temperature histories. The "Auger seal", "BV52", and "BV53 seal" locations were chosen to determine if the seal materials were adequate. While expensive and difficult to use, metal o-rings were used here to withstand the high temperatures indicated by the steady state model. However, the actual temperatures were lower than expected and in an acceptable range to use Grafoil seals, which are less expensive and easier to use. The "rover bracket" location never exceeded $50{ }^{\circ} \mathrm{C}$, and would thus be even lower at the bolts. This is within the temperature requirements of the rover frame.

\section{Auger Speed Effect}

The rotation of the auger serves two primary functions. Foremost, it mixes the soil to improve heat transfer from the core heater. Secondly, it prevents any bridging or soil 'sintering' (ref. 3) at high temperatures. The rotational speed of the auger on completed reactor is fixed at $14 \mathrm{rpm}$. However, this parameter was explored prior to final assembly.

Figure 7 shows the affect of auger speed on the temperature distribution through the soil (tephra). At a lower auger speed (thick lines), the soil near the auger heated quickly, and thus the core heater reached its set-point temperature quickly. The core heater was essentially being "insulated" by the slow moving soil. This meant that the temperature difference in the soil (core versus wall temperature) was large, $450{ }^{\circ} \mathrm{C}$ in this case. At a higher auger speed (thin lines) the temperature difference was reduced, but the core heater never reached its set-point temperature. While increasing the auger speed improved heat transfer in the soil, heat was drawn away from the core heater more quickly. 


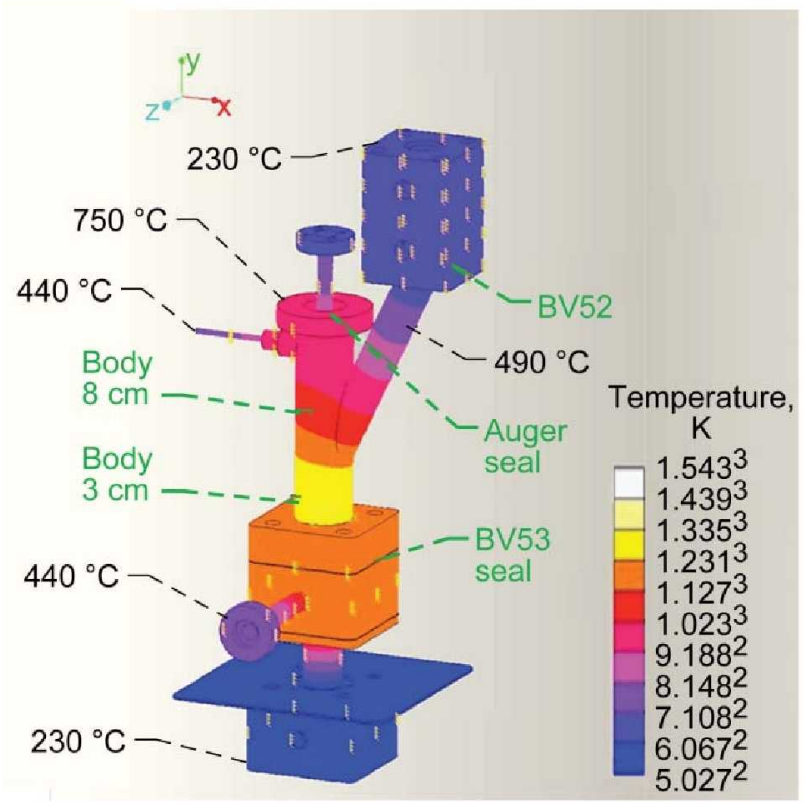

Figure 5.-The calculated steady state temperature distribution over the reactor surface with the soil at $1000^{\circ} \mathrm{C}$. The green labels indicate thermocouple positions used in the experimental measurements shown in figure 6.

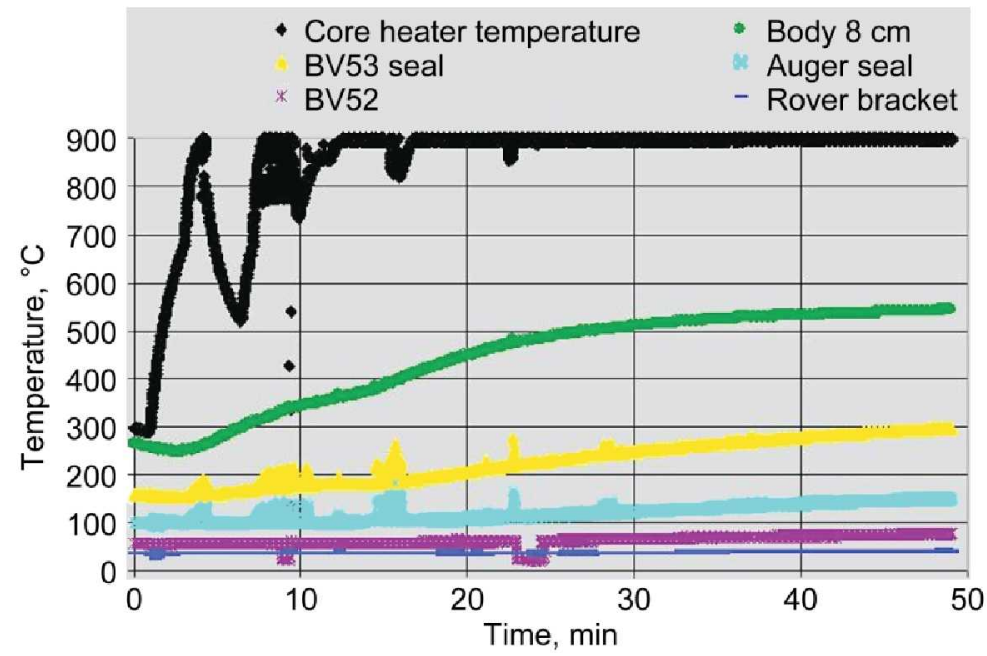

Figure 6.-Thermocouple measurements at various locations across the reactor surface with the core heater at $900{ }^{\circ} \mathrm{C}$. The thermocouple labels correspond to the locations shown in figure 5 . The temperatures drops early in the test were due to a temporary electrical malfunction. 


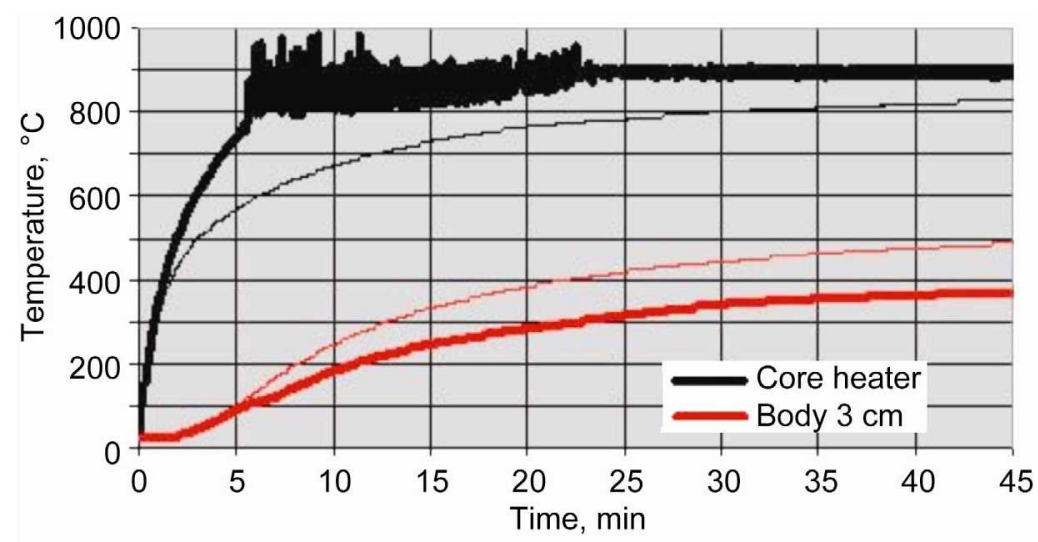

Figure 7.-Comparison of temperature profiles during heating tests at two different auger rotation speeds (38 rpm, core heater set-point $1000^{\circ} \mathrm{C}$ versus $5 \mathrm{rpm}$, set-point $900^{\circ} \mathrm{C}$ (thick lines)). The temperature location labeled "body $3 \mathrm{~cm}$ " was located on the reactor body $3 \mathrm{~cm}$ from the lower flange.

The practical consequence is that for low auger speed the soil nearest the auger will reach the desired temperature. Therefore, the soil in this hot spot will react readily with the flowing hydrogen. However, the reaction rate will fall off quickly as radial distance increases. This may be acceptable if the test goal is to obtain a specific oxygen yield. However, if the test goal is to characterize the soil in terms of total oxygen content and reactivity, a more uniform elevated soil temperature, thus higher auger speed, would be preferable.

\section{Gas Flow Effect}

During the oxygen extraction operation, hydrogen gas is re-circulated through the reactor. While this gas flow enables oxygen extraction, it also removes heat from the soil. Compressed air, in lieu of hydrogen, was used in the laboratory to test the effect of gas flow on the temperature profile. The anticipated flow rate of hydrogen is no greater than $3 \mathrm{slpm}$. Using a ratio of viscosities between air and hydrogen, the equivalent fluidization flow rate of air is $1.44 \mathrm{slpm}$.

The results of the test are shown in figure 8. In two instances, the flow was briefly turned off (the white highlighted regions), to emphasize the flow effect. During these periods, the core heater temperature increased nearly $100{ }^{\circ} \mathrm{C}$, proving that the heat loss to the flow had a significant impact on the soil temperature distribution. In order to mitigate this and other unexpected heat loss factors, an additional external wall heater was added. In figure 8 this wall heater was activated $1 \mathrm{hr}$ into the test, and successfully corrected for the heat loss to the flow.

\section{E. Soil Characteristics}

Soil from the field demonstration site, known as tephra, was used in the majority of the laboratory testing. This soil was dried to remove ground moisture prior to testing. The raw soil sample has a wide range of particle sizes (fig. 9). In the integrated hardware, a crusher would prevent material larger than $1 \mathrm{~mm}$ from entering the reactor. In lieu of the crusher, a sieve was used filter the particles to this size. The bulk density of the sieved sample was measured to be $1.35 \pm 0.06 \mathrm{~g} / \mathrm{cm}^{3}$.

The soil was visibly altered after exposure to the elevated $\left(900^{\circ} \mathrm{C}\right)$ temperatures. Similar physical alteration has also been observed for JSC1-a regolith simulant (which was used in previous reactor testing (ref. 1)). In the case of the tephra soil, it became darker with orange specs of color (fig. 9). At $150^{\circ} \mathrm{C}$ little water vapor was recovered. However, a greater amount of was released during heating to $900{ }^{\circ} \mathrm{C}$ (no hydrogen flow, just elevated temperature). 


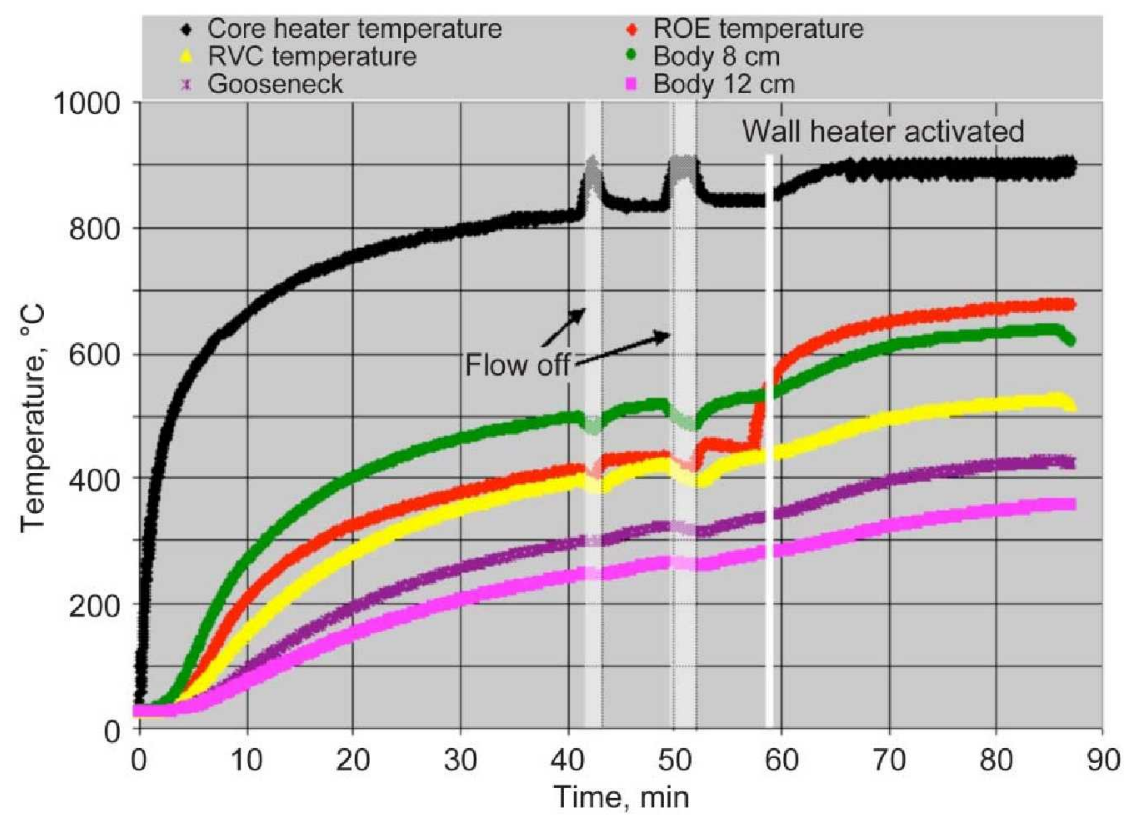

Figure 8.-Temperature profiles for heating test with a flow of air though the reactor. The air flow was meant to mimic the effect of the hydrogen flow that will be used to extract oxygen from the soil. (ROE heating with air flow of $1.44 \mathrm{slpm}$ core heater set-point $900^{\circ} \mathrm{C}$, auger: $14 \mathrm{rpm}$ ).

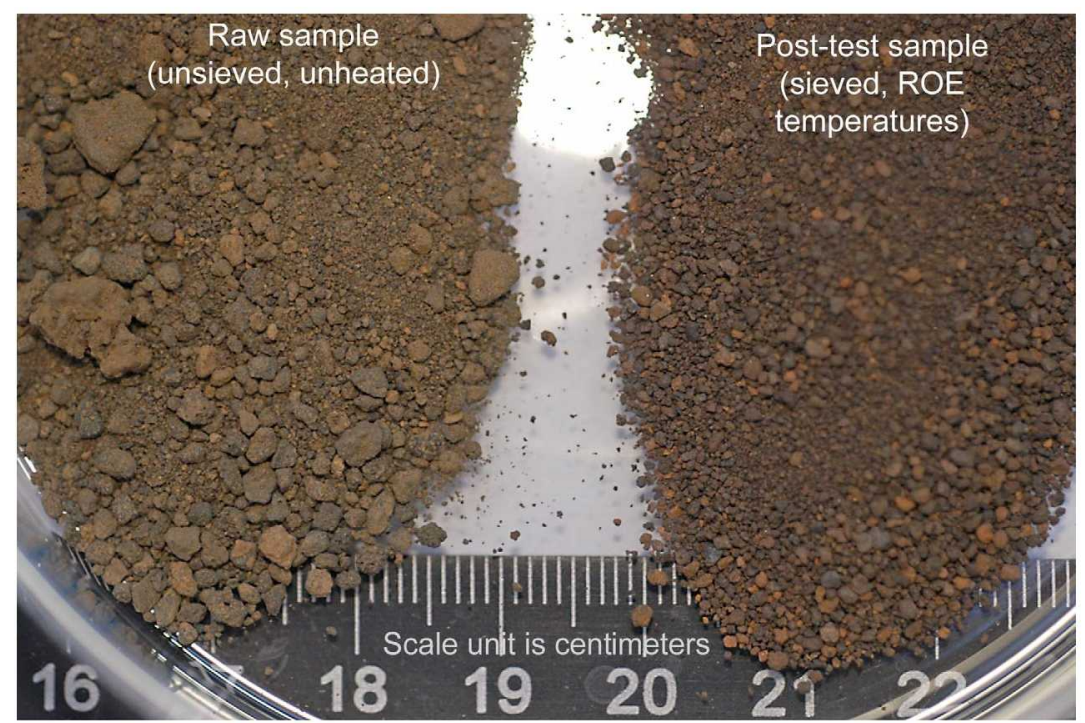

Figure 9.-Comparison of tephra before and after sieving and heating. 


\section{Numerical Modeling}

In parallel to the experimental efforts, numerical modeling of the reactor heating process was also carried out. The objective of the modeling effort was to examine the thermal characteristics of the lunar soil simulant in the reactor as it undergoes the mixing and heating process. This information is useful to future reactor hardware development and experimental design. These models focused on the JSC1-a regolith simulant that is frequently used in laboratory testing.

\section{A. Methodology}

The material in the reactor consists of loose particles of regolith simulant and air, stirred by the rotating auger. Therefore, the heat transport mechanisms are that of granular materials, including diffusive, convective and dissipative heat generation. The heat generated by dissipation of kinetic energy is small in comparison with the heat from the core heater, thus this term in the energy equation was neglected from the model. Because of lack of knowledge of particle shape geometry and its distribution, detailed modeling of particle motion and air flow is not possible. Instead, the simulant/air mixture in the reactor was treated as a stationary composite material. In this approach, the contribution of the convective transport in the energy equation from both solid and gas phases are lumped into the diffusion term. Therefore, the actual mixture and the fictitious composite material have identical external thermal characteristics. This is similar to the way heat pipes are treated. Although actual processes in a heat pipe involve evaporation, condensation, capillary flow, etc., a heat pipe can be viewed externally as a conductive rod with very high apparent thermal conductivity. With this lump sum approach, the apparent thermal conductivity accounts for both molecular diffusion and convective transport due to mixing. In the present case, the apparent thermal conductivity is expected to be a function of the auger rotation rate, which represents the extent of the mixing and the particle motion.

\section{B. Model Approach}

In order to obtain the apparent thermal properties of this fluidized granular media, a 'reverse engineering' approach was used. In other words, the thermal properties in the model were adjusted to obtain the best match to the existing experimental data. The temperature histories of three thermocouples, thermocouple nos. 1 to 3 in figure 10, were compared to similarly located thermocouples from the experiment. Thermocouple no. 1 was located inside the core heater and the other two were located on the outer wall of the reactor. Thermocouple no. 2 was at the middle of the simulant loaded section, corresponding to the position labeled "ROE" in figure 2 , while thermocouple no. 3 was above the simulant loaded section corresponding to the "RVC" position. The reason that the temperature histories were chosen as the matching targets for the model is twofold. First, the experiment covers a wide range of temperatures, thus any temperature dependencies in the simulant thermal properties would be apparent. Second, all tests began at room temperature, uniform over the whole region, which is a well defined and convenient initial condition for the model.

The core heater was modeled in detail based on the drawing provided by the manufacturer. The metal casing and the insulation powder filling are modeled exactly. A heat source term is added in the area where the electric heating coil is located. The strength of the source term, or the power density, is the actual power applied to the heater divided by the total volume of the heating element.

A large volume of room air was included in the computational domain, where full Navier-Stokes equations were solved. By including this volume of air in the domain, the use of heat transfer coefficients on the wall of the reactor can be avoided. If the computational domain only included the reactor, heat transfer coefficients along the surface of the reactor would be necessary to describe the boundary conditions of the model. Heat transfer coefficients, in general, are mostly obtained from experimental measurements and are strongly case-specific. Thus, it is difficult to find accurate coefficients that can be applied to this particular case with confidence. 


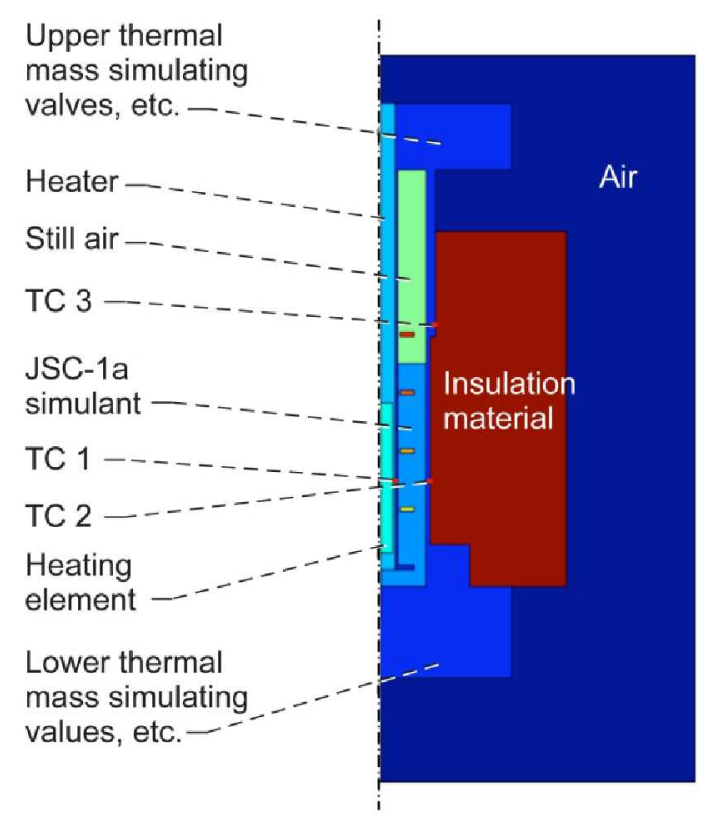

Figure 10.-An enlarged view of the model geometry showing details of the reactor. The only heat source shown in this figure is the heating element inside the core heater. The upper and the lower thermal masses simulate valves and related reactor components. The spiral auger fin is simulated by 5 circular rings that cover the same vertical length as the actual auger.

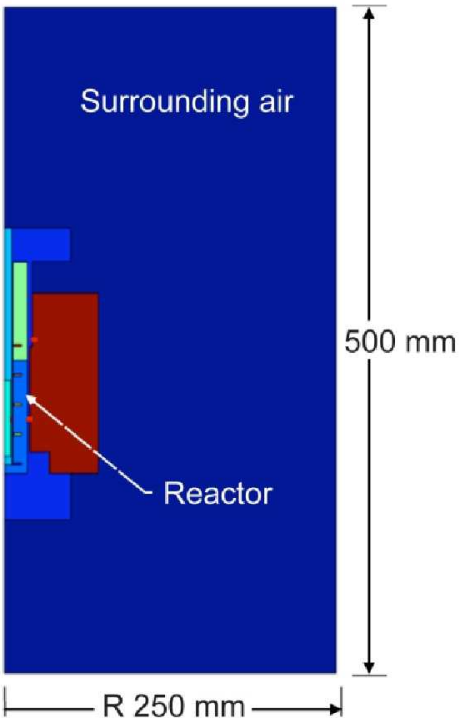

Figure 11.-The entire computational domain of the model. A large volume of room air surrounding the reactor is included, where nonisothermal Navier-Stokes equations are solved for temperature and velocity distribution so that use of heat transfer coefficient along the reactor surface can be avoided.

Three test cases were run, at conditions matching the experiments. The soil used in both the experiment and model was JSC1-a. Core heater temperature and auger rotation rate were varied. An external wall heater (as described in section III.B.) was employed in one test. This heater was placed on the outer wall of the reactor (yet inside the insulation cover) in the simulant loaded region. The experimental data used was obtained early in the testing program, such that the auger and wall heater designs were improved in proceeding tests. However the experimental setup used for these tests is considered to be a high fidelity model of the final reactor.

\section{Domain Geometry}

The numerical model was established using commercially available software, COMSOL, which solves coupled heat transfer and fluid flow problems.

The entire computational domain is a cylinder, with a $500 \mathrm{~mm}$ diameter and $500 \mathrm{~mm}$ height. The reactor is located at the center of the cylinder surrounded by a large volume of room air, as shown in figure 11. The actual structure of the reactor assembly is rather complicated (fig. 1) such that a higher fidelity geometry would require a three-dimensional model and more computing power than what is available for the present work.

Figures 10 and 11 illustrate the simplified reactor geometry used in the model. In this axisymmetric model, the spiral auger flights were simulated by five equally spaced circular rings of the same material. The inner and outer diameters, the thickness, and the vertical coverage of these rings on the core heater match the dimensions of the physical auger. The external wall heater, which also has a spiral shape, was treated in the same manner as the auger, i.e., it was replaced by four separated rings of thin wires, covering the same total area as the actual heater. The effect of the regolith inlet chute on the heat conduction was modeled by increasing the thickness of the reactor wall in that area. Similarly, the upper 
and lower ball valves are simulated by cylindrical masses which have similar mass and the surface areas of the actual parts. Because these components are relatively far away from the heating element and the simulant loaded region, their effects are considered in an integral sense, i.e., the detail temperature distribution in this region is not important, but the total heat flux and heat capacity should mimic the real case. The material properties and the geometry of the rest of the reactor are consistent with those specified in the design drawings.

\section{Results}

Results of three successful modeling cases are presented below. The three experimental conditions were:

(1) An auger rotation rate of $15 \mathrm{rpm}$, and a core heater set-point of $600^{\circ} \mathrm{C}$.

(2) An auger rotation rate of $20 \mathrm{rpm}$, and a core heater set-point of $900^{\circ} \mathrm{C}$.

(3) An auger rotation rate of $36 \mathrm{rpm}$, a core heater was set-point of $1000{ }^{\circ} \mathrm{C}$, and an external wall heater powered at $81.4 \mathrm{~W}$.

The core heater set-point did not have a significant impact on the model since only the transient portion of the heating process was modeled. During this period, the core heater operated at full power of 181.7 W. Thus, in all three cases, the heat generation rate of the core heater was equal and constant. These three cases were chosen to explore the effect of the auger speed on the apparent thermal properties of the simulant. Different auger speeds represent different mixing regimes between the simulant particles and between the particles and air. Figure 12 shows the comparison between the experimental and the simulation data for these three cases.

The apparent thermal conductivity and specific heat that best fit the experimental results in the three cases are:

Test no. 1: $15 \mathrm{rpm}$ auger speed: $k=0.18+0.0005 T$ and $c=1400+0.03 T$.

Test no. 2: $20 \mathrm{rpm}$ auger speed, $k=0.33+0.0005 T$ and $c=1400+0.03 T$.

Test no. 3: $36 \mathrm{rpm}$ auger speed, $k=0.38+0.0005 T$ and $c=1400+0.03 T$.

The apparent thermal conductivity of the simulant/air mixture at $36 \mathrm{rpm}$ is only $0.63 \mathrm{~W} / \mathrm{m}^{\circ} \mathrm{C}$ at $500{ }^{\circ} \mathrm{C}$, whereas that of the ceramic insulation material used on the reactor walls is $1.68 \mathrm{~W} / \mathrm{m}^{\circ} \mathrm{C}$. Even with mixing, the thermal conductivity of the simulant is less than a half of that of the insulation material.

\section{E. Discussion}

In order to match the experimental temperature history, the model parameters ( $k$ and $c$ ) were assumed to have a temperature dependency. The apparent specific heat $(c)$ is relatively insensitive to temperature change; a $1000{ }^{\circ} \mathrm{C}$ temperature change resulted in a specific heat change of about 2.1 percent. The apparent thermal conductivity $(k)$ increased with increasing temperature.

The low thermal conductivity of the simulant resulted in a steep temperature drop radially from the core heater. The addition of the external wall heater improved temperature uniformity, as shown in figure 13. The image on the left (fig. 13(a)) shows the temperature distribution for a case using only the core heater, while the right image (fig. 13(b)) is a case with both the core and wall heater. The mixing speeds were 20 and $36 \mathrm{rpm}$, respectively. Both temperature distributions were taken $540 \mathrm{~min}$ after the heaters were powered. Although the temperature distribution is more uniform when the wall heater is active, the distribution is still quite large. This is even more apparent in figure 14 which shows radial temperature profiles across the red horizontal lines in figure 13. This suggests that further increase the power of the coil heater is necessary for more uniform temperature distribution over the simulant region. 

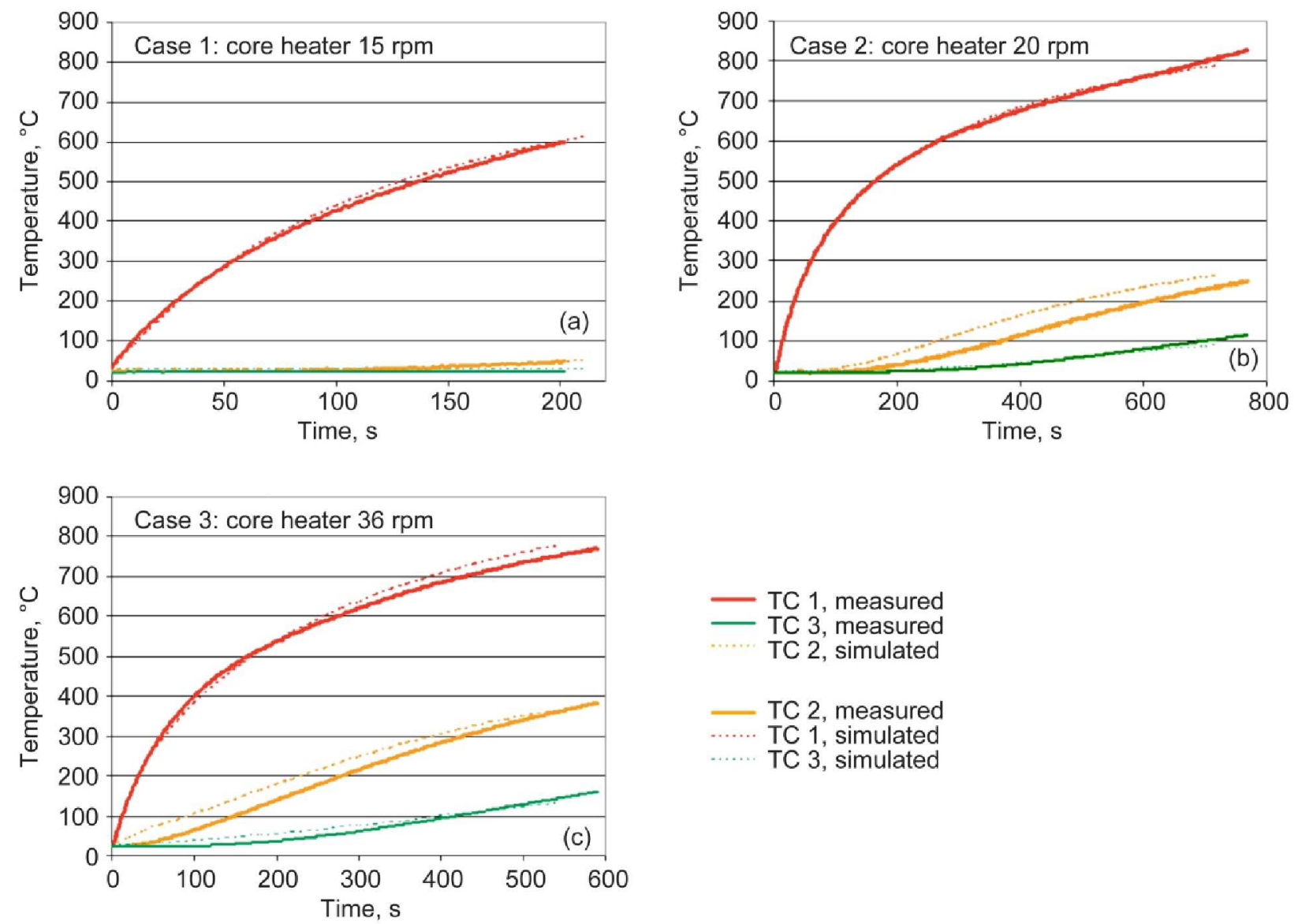

Figure 12.-The modeling results as compared to the experimental for the three cases. (a) Case 1; auger at $15 \mathrm{rpm}$, with only core heater active. (b) Case 2; auger at $20 \mathrm{rpm}$, with only the core heater active. (c) Case 3; auger at $36 \mathrm{rpm}$, both core heater and wall heater were active. 


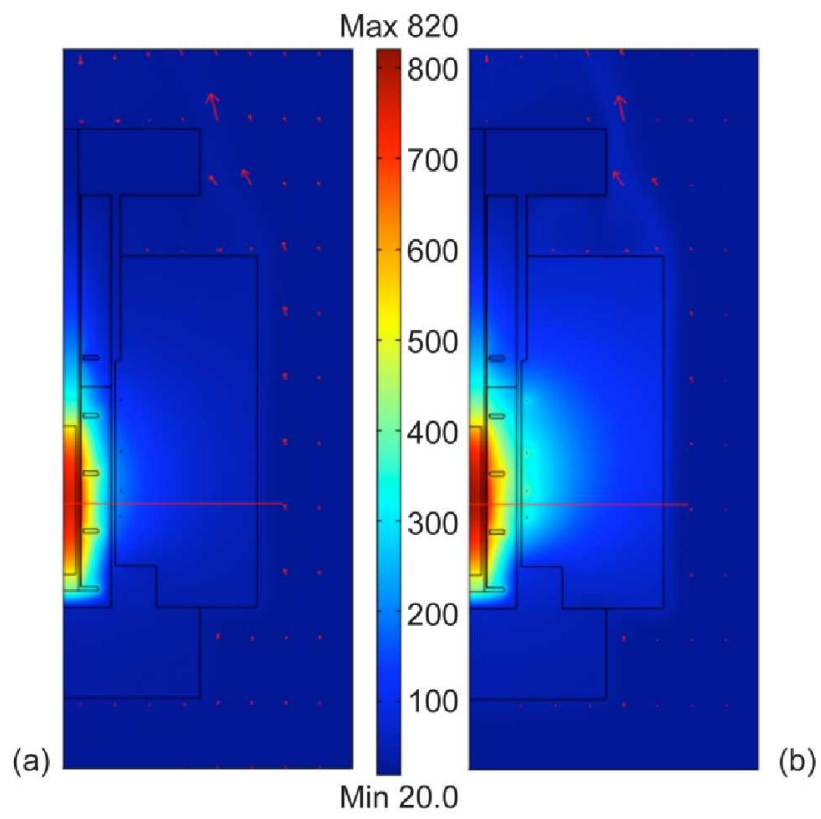

Figure 13.-Temperature maps of two cases to show the effect of the wall heater. In (a) only the core heater is active, whereas in (b) both the core and wall heater are used. The horizontal red lines indicate the location of the temperature profile plotted in figure 14.

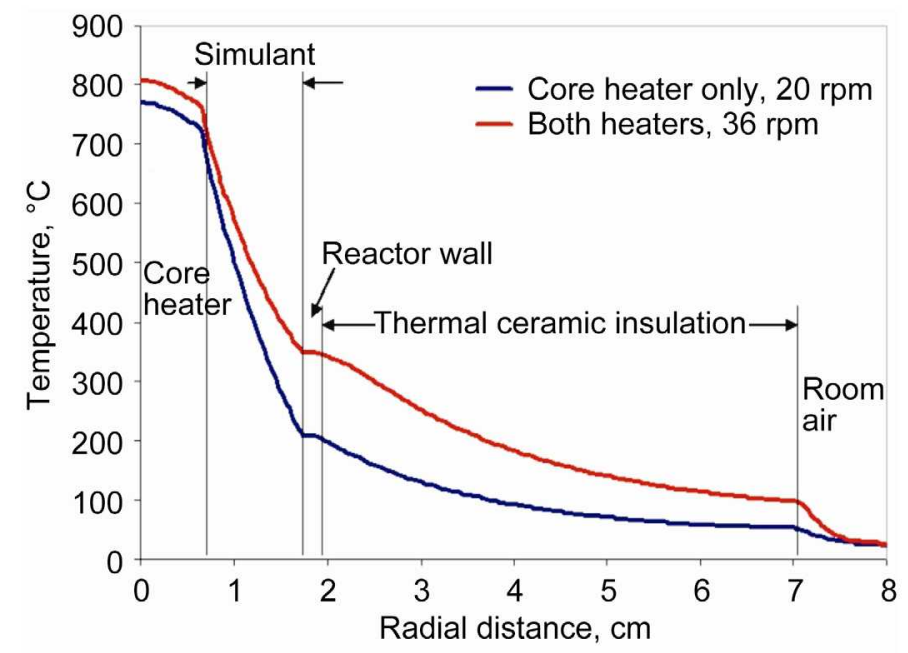

Figure 14.- Spatial temperature profiles of two cases taken $540 \mathrm{~min}$ after heaters were powered. One case only uses the core heater, whereas the other uses both core heater and wall heater. In both cases, significant temperature drop over the simulant region occurs. The wall heater can mitigate this problem depending on the input power to the heater. 


\section{V.Conclusion}

The results of the laboratory reactor testing and the associated modeling efforts provide valuable knowledge for the field demonstration as well as future reactor development. The ball valve seals were successful, with the measured leak rates well within acceptable limits. Likewise, the temperature at critical interface points on the reactor was better than predicted, permitting the use of some more cost effective materials. Both experimental and modeling results highlighted the usefulness of a hybrid heating scheme consisting of a core heater and an external wall heater. The use of the wall heater improved temperature uniformity in the soil, and in cases where the auger speed was high or when a gas flow was active, it was needed in order to achieve the desired set-point temperature. Optimization of auger speed and wall heater power could further improve temperature uniformity and reduce over heating time. The apparent thermal properties of the gas/soil particle mixture were dependant on auger speed, as well as the system geometry. These properties were determined by iterating the model parameters to match the experimental results. Temperature dependant equations for both conductivity and specific heat were determined for three representative cases. These results show that the apparent thermal conductivities of gas/soil particle mixture are very low, even at the higher auger speeds. This suggests that to achieve uniform temperature distribution, reactor configurations with small length scales between heating elements should be considered for future design. 



\section{Appendix-Material Properties}

The material properties used in the numerical model are listed in table 1.

TABLE 1.-THE THERMAL PROPERTIES USED IN THE NUMERICAL MODEL; FOR THE REACTOR MATERIALS

\begin{tabular}{|l|c|c|c|}
\hline \multicolumn{1}{|c|}{ Material } & $\begin{array}{c}\text { Density, } \\
\mathrm{kg} / \mathrm{m}^{3}\end{array}$ & $\begin{array}{c}\text { Thermal conductivity, } \\
\mathrm{W} / \mathrm{m}^{\circ} \mathrm{C}\end{array}$ & $\begin{array}{c}\text { Specific heat, } \\
\mathrm{J} / \mathrm{kg}^{\circ} \mathrm{C}\end{array}$ \\
\hline Inconel & 8440 & 12 & 440 \\
\hline Kaowool RT Blanket & 128 & $0.48+0.0006 \mathrm{~T}+3.6 \mathrm{~T}^{2}$ & $747.8+0.7 \mathrm{~T}-0.0006 \mathrm{~T}^{2}$ \\
\hline Magnesium Oxide Powder & 3580 & 9 & 800 \\
\hline
\end{tabular}

Inconel was used for the sheath of the core heater and the reactor body, including the upper and lower thermal masses. Kaowool RT Blanket is ceramic fiber thermal insulation used around reactor body to reduce the heat loss to the surrounding air. Magnesium Oxide Powder was used as the filling material in the core heater. It functions as an insulation material that separates the heating wire from the sheath of the heater.

Properties of air, which are functions of temperature and pressure, were called out from the database automatically linked to the COMSOL software. These functions are well established and can be found in various literature. 


\section{References}

1. Kleinhenz, J.E., Sacksteder, K.R., and Nayagam, V., "Lunar Resource Utilization: Development of a Reactor for Volatile Extraction from Regolith," AIAA Aerospace Sciences Meeting and Exhibit, 092407, Reno, NV, 2008.

2. Bartlett, P., Wettergreen, D., and Whittaker, W.L. "Design of the Scarab Rover for Mobility and Drilling in the Lunar Cold Traps," International Symposium on Artificial Intelligence, Robotics and Automation in Space, February, 2008.

3. Cooper, B.L., "Sintering of Lunar and Simulant Glass," AIAA Space Technology and Applications International Forum, CP969, Albuquerque, NM, 2008. 


\begin{tabular}{|c|c|c|c|c|c|}
\hline \multicolumn{5}{|c|}{ REPORT DOCUMENTATION PAGE } & $\begin{array}{c}\text { Form Approved } \\
\text { OMB No. 0704-0188 }\end{array}$ \\
\hline \multicolumn{6}{|c|}{ 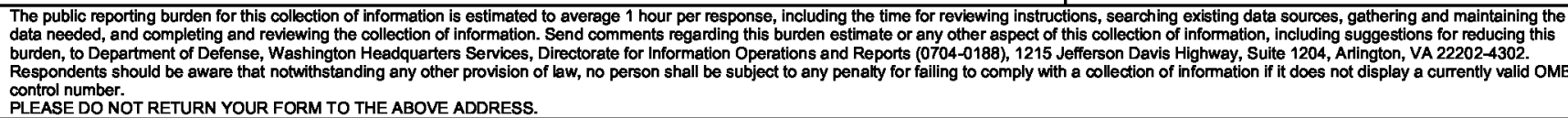 } \\
\hline \multicolumn{2}{|c|}{$\begin{array}{l}\text { 1. REPORT DATE (DD-MM-YYYY) } \\
01-07-2009\end{array}$} & \multicolumn{3}{|c|}{$\begin{array}{l}\text { 2. REPORT TYPE } \\
\text { Technical Memorandum }\end{array}$} & 3. DATES COVERED (From - To) \\
\hline \multirow{3}{*}{\multicolumn{5}{|c|}{$\begin{array}{l}\text { 4. TITLE AND SUBTITLE } \\
\text { Development of a Reactor for the Extraction of Oxygen and Volatiles From Lunar Regolith }\end{array}$}} & 5a. CONTRACT NUMBER \\
\hline & & & & & 5b. GRANT NUMBER \\
\hline & & & & & 5c. PROGRAM ELEMENT NUMBER \\
\hline \multirow{3}{*}{\multicolumn{5}{|c|}{$\begin{array}{l}\text { 6. AUTHOR(S) } \\
\text { Kleinhenz, Julie; Yuan, Zengguang; Sacksteder, Kurt; Caruso, John }\end{array}$}} & 5d. PROJECT NUMBER \\
\hline & & & & & 5e. TASK NUMBER \\
\hline & & & & & $\begin{array}{l}\text { 5f. WORK UNIT NUMBER } \\
\text { WBS 387498.04.01.03.01.03 }\end{array}$ \\
\hline \multicolumn{5}{|c|}{$\begin{array}{l}\text { 7. PERFORMING ORGANIZATION NAME(S) AND ADDRESS(ES) } \\
\text { National Aeronautics and Space Administration } \\
\text { John H. Glenn Research Center at Lewis Field } \\
\text { Cleveland, Ohio 44135-3191 }\end{array}$} & $\begin{array}{l}\text { 8. PERFORMING ORGANIZATION } \\
\text { REPORT NUMBER } \\
\text { E-16937 }\end{array}$ \\
\hline \multirow{2}{*}{\multicolumn{5}{|c|}{$\begin{array}{l}\text { 9. SPONSORING/MONITORING AGENCY NAME(S) AND ADDRESS(ES) } \\
\text { National Aeronautics and Space Administration } \\
\text { Washington, DC 20546-0001 }\end{array}$}} & $\begin{array}{l}\text { 10. SPONSORING/MONITOR'S } \\
\text { ACRONYM(S) } \\
\text { NASA; AIAA }\end{array}$ \\
\hline & & & & & $\begin{array}{l}\text { 11. SPONSORING/MONITORING } \\
\text { REPORT NUMBER } \\
\text { NASA/TM-2009-215621; AIAA-2009- } \\
1203\end{array}$ \\
\hline \multicolumn{6}{|c|}{$\begin{array}{l}\text { 12. DISTRIBUTON/AVAILABILITY STATEMENT } \\
\text { Unclassified-Unlimited } \\
\text { Subject Category: } 91 \\
\text { Available electronically at http://gltrs.grc.nasa.gov } \\
\text { This publication is available from the NASA Center for AeroSpace Information, 433-757-5802 }\end{array}$} \\
\hline \multicolumn{6}{|c|}{ 13. SUPPLEMENTARY NOTES } \\
\hline \multicolumn{6}{|c|}{$\begin{array}{l}\text { 14. ABSTRACT } \\
\text { The RESOLVE (Regolith and Environment Science, Oxygen and Lunar Volatiles Extraction) Project, aims to extract and quantify useful } \\
\text { resources from lunar soil. The reactor developed for RESOLVE is a dual purpose system, designed to evolve both water, at } 150{ }^{\circ} \mathrm{C} \text { and up to } \\
80 \text { psig, and oxygen, using hydrogen reduction at } \sim 900^{\circ} \mathrm{C} \text {. A variety of laboratory tests were performed to verify its operation and to } \\
\text { explore the properties of the analog site soil. The results were also applied to modeling efforts which are being used to estimate the apparent } \\
\text { thermal properties of the soil. The experimental and numerical results, along with the analog site tests, will be used to evolve and optimize } \\
\text { future reactor designs. }\end{array}$} \\
\hline \multicolumn{6}{|c|}{$\begin{array}{l}\text { 15. SUBJECT TERMS } \\
\text { Lunar resources; In-situ resource utilization; Oxygen production; Lunar exploration }\end{array}$} \\
\hline \multicolumn{3}{|c|}{ 16. SECURITY CLASSIFICATION OF: } & $\begin{array}{l}\text { 17. LIMITATION OF } \\
\text { ABSTRACT }\end{array}$ & $\begin{array}{l}\text { 18. NUMBER } \\
\text { OF }\end{array}$ & $\begin{array}{l}\text { 19a. NAME OF RESPONSIBLE PERSON } \\
\text { STI Help Desk (email:help@sti.nasa.gov) }\end{array}$ \\
\hline $\begin{array}{l}\text { a. REPORT } \\
\text { U }\end{array}$ & $\begin{array}{l}\text { b. ABSTRACT } \\
\text { U }\end{array}$ & $\begin{array}{l}\text { C. THIS } \\
\text { PAGE } \\
\text { U }\end{array}$ & UU & $\begin{array}{l}\text { PAGES } \\
23\end{array}$ & $\begin{array}{l}\text { 19b. TELEPHONE NUMBER (Include area code) } \\
433-757-5802\end{array}$ \\
\hline
\end{tabular}



